\title{
RESEARCH
}

Open Access

\section{Effect and safety of intraoperative intraperitoneal chemotherapy on patients suffering from colorectal cancer}

\author{
An Shang ${ }^{1 \dagger}$, Shuang Wang ${ }^{2+}$, Yongping Yang ${ }^{1}$, Liping $\mathrm{Li}^{3}$, Zeyun Zhao ${ }^{1}$, Donglin $\mathrm{Li}^{1}$, Yu Guo ${ }^{1}$ and Min Wang ${ }^{{ }^{*}}$ (D)
}

\begin{abstract}
Background: Colorectal cancer (CRC), the third most commonly diagnosed malignant carcinoma and the third most common cause of carcinoma-related mortality, continues to be a major international health problem. And approximately $33 \%$ of patients suffer from recurrence after radical surgery. Free malignant cell implanting in the peritoneum is generally accepted as one of the main reasons of such outcome. We did this present clinical study with the aim of evaluating the effects and safety of intraoperative intraperitoneal chemotherapy (IOC) on patients suffering from colorectal cancer, with hoping to find a novel, effective, and available approach to deal with malignant cell implanting during surgeries.

Methods: In total, 391 patients who went through colorectal radical surgery were considered eligible between June 1, 2017, and December 31, 2018. 220 patients were treated with surgery without IOC, while other 171 patients received surgery plus IOC. Clinical characteristics, operative findings, postoperative short-term outcomes, diseasefree survival (DFS), and overall survival (OS) were compared between these above 2 groups in the selected population.
\end{abstract}

Result: The present research included 391 patients (251 men and 140 women) who underwent surgery without IOC $(n=171)$ or surgery plus IOC $(n=220)$, with a mean (SD) age of 60.4 (9.7) years in the surgery without IOC group and 60.6 (8.7) in the surgery plus IOC group $(P=.85)$. No significant differences were witnessed between the two groups in surgery-related information and postoperative complications. It is worth noting that IOC independent of other factors was associated with a favor prognosis in CRC patients with stage II/III (HR 0.50, 95\%Cl $0.30-0.82, P=.006)$. Moreover, for patients with stage II colorectal carcinoma, DFS did not differ between two groups ( $P=.553$, Kaplan-Meier log-rank), and OS was no exception. In stage III CRC patients, the estimated DFS rate for patients receiving IOC was $82.2 \%$ and patients without IOC was $66.4 \%$ after 3 years, which demonstrated that IOC was associated with a favorable prognosis in stage III patients ( $P=.012$, Kaplan-Meier log-rank). Furthermore, the differences were still remained between the two groups when considering the influence about postoperative chemotherapy ( $P=.014$, Kaplan-Meier log-rank). IOC can also significantly improve patients' overall survival whether they get treatment with POC ( $P=.006$, Kaplan-Meier log-rank; $P=.025$, Kaplan-Meier log-rank).

(Continued on next page)

\footnotetext{
* Correspondence: jdeywangmin@163.com

${ }^{\dagger}$ The authors An Shang and Shuang Wang has similar contribution to the manuscript.

${ }^{1}$ Colorectal Section, Department of Surgery, The Second Hospital of Jilin University, No. 218, Ziqiang Dist, Changchun 130041, Jilin, China

Full list of author information is available at the end of the article
}

(c) The Author(s). 2021 Open Access This article is licensed under a Creative Commons Attribution 4.0 International License, which permits use, sharing, adaptation, distribution and reproduction in any medium or format, as long as you give appropriate credit to the original author(s) and the source, provide a link to the Creative Commons licence, and indicate if changes were made. The images or other third party material in this article are included in the article's Creative Commons licence, unless indicated otherwise in a credit line to the material. If material is not included in the article's Creative Commons licence and your intended use is not permitted by statutory regulation or exceeds the permitted use, you will need to obtain permission directly from the copyright holder. To view a copy of this licence, visit http://creativecommons.org/licenses/by/4.0/. The Creative Commons Public Domain Dedication waiver (http://creativecommons.org/publicdomain/zero/1.0/) applies to the data made available in this article, unless otherwise stated in a credit line to the data. 
(Continued from previous page)

Conclusions: In the present study, we have found that surgery plus IOC generated a favorable prognosis for stage III CRC patients but not stage II without any side-effects when the dosage of lobaplatin was $0.1 \mathrm{~g} / \mathrm{L}$. As a new, safe, and simple procedure, IOC therapy is easily performed - and does not require any special devices or techniques. Thus, IOC is a promising and exciting therapeutic strategy for patients with CRC.

\section{Introduction}

Following lung cancer and breast cancer in females and lung cancer and prostate cancer in males respectively, colorectal cancer, the third most commonly diagnosed malignant carcinoma and the third most common cause of carcinoma-related mortality, a major international health problem [1]. Although the total quantity of CRC is still the highest in Western countries, the incidence and mortality there tend to be stabilized or even decreased; however, the trend of morbidity and mortality seems to bet the opposite outcomes in many developing countries, such as China [2]. Currently, radical resection remains the reference-standard treatment for early and even advanced cancer. The standard strategy of treatment for CRC, besides radical resection, is intravenous chemotherapy. Nevertheless, approximately $33 \%$ of patients suffer from recurrence after radical surgery [3]. Extraordinary, peritoneal carcinomatosis, as a common type of CRC metastasis, has long been regarded as associating with poor prognosis for patients after radical surgery, and whose overall survival is even as poor as the multiple-organ metastases [4-6]. That outcome would partially due to the insensitivity to systemic chemotherapy for peritoneal metastasis [7].

Peritoneal-free cancer cell (PFCC) implanting in the peritoneum is generally accepted to be one of the main reasons of carcinoma recurrence [8]. Consequently, it is necessary to kill free malignancy cells before fixation on the peritoneum [9]. Cytoreductive surgery (CRS) with hyperthermic intraperitoneal chemotherapy (HIPEC) has been recommended as an alternative approach for patients who have undergone $\mathrm{R} 0$ resection and resist cancer recurrence in the peritoneum [10]. However, it cannot be ignored that high morbidity and mortality restrict the application of HIPEC [11-13]. It is worth noting that opening lymphatic channels during operation might spread viable cancer cells into the abdominal cavity, which certainly provides evidence of the effectiveness of intraoperative intraperitoneal chemotherapy [8]. However, the most suitable medicine for IOC is still controversial. Lobaplatin (chemical formula: C9H18N2O3Pt) exerts stronger anti-neoplastic effects with fewer adverse effects as a third-generation platinum anti-neoplastic agent [14]. And GSDME-dependent pyroptosis as a possible mechanism for lobaplatin to eradicate colorectal neoplastic cells has been confirmed [15]. Furthermore, several studies has indicated that perfusion chemotherapy with lobaplatin can suppress proliferation and peritoneal metastasis of colorectal cancer and promote a favorable prognosis for CRC without any side effects [16, 17]. Therefore, lobaplatin may be a relatively better choice for IOC.

Though intraoperative intraperitoneal chemotherapy as a new strategy to improve prognosis after R0 resection for CRC has been confirmed valid [18], further research is still needed to figure out whether it can prolong overall survival (OS) time, prevent peritoneal metastasis following the radical operation and any associated complications. We did the study with the aim of evaluating the effect and safety of intraoperative intraperitoneal chemotherapy on patients with colorectal cancer.

\section{Method \\ Patients}

The retrospective study has met with approval by the ethics committee of The Second Affiliated Hospital of Jilin University and performed in accordance with the Helsinki Declaration of World Medical Association, and the demand of patient informed consent was deserted because of the retrospective nature of this study. After rigorous screening, eventually, 391 patients who went through colorectal radical surgery were considered to be eligible from June 1, 2017, to December 31, 2018, in our department. The baseline characteristics of the selected patients, consisting of age, gender, diabetic mellitus, hypertension, tumor location, tumor size, pathologic $\mathrm{T}$ category, pathologic $\mathrm{N}$ category, TNM stage (based on the postoperative pathology), degree of differentiation, tumor pathologic type, postoperative adjust chemotherapy, and carcinoma embryonic antigen (CEA) before the operation was carefully collected from medical records. Primary locations of tumors were defined as the right colon (from the cecum to the transverse colon), left colon (from the splenic flexure to the rectosigmoid flexure), and rectum (15 $\mathrm{cm}$ from the anal verge).

The intra- and post-operation date, consisting of operation method, operation time, amount of intraoperative blood loss, time to first flatus, LOS (length of stay), abdominal pain, and laboratory results (such as white blood cell count, neutrophil count, neutrophillymphocyte ratio, hemoglobin, albumin, and albumin 
globulin ratio), $48 \mathrm{~h}$ after the operation was also collected through consulting patients' medical notes. Follow-up information was obtained at an outpatient clinic of our center or using a telephone questionnaire directly. The final follow-up date for all of the cases was on December 1, 2020; Disease-free survival (DFS) is defined as the time from radical operation to recurrence of tumor or death, and overall survival (OS) is defined as the time from radical operation to death.

Visual Analogue Scale/Score (VAS), ranging from 0 to $10(0$, no pain; 1 to 3 , mild pain [sustainable, sleep is not affected], 4 to 6, moderate pain [sleep is affected and painkillers are usually needed], 7 to 10 , severe pain [Sleep is severely disrupted and painkillers are necessary]), was applied to evaluate the pain degree of postoperative patients [19]. In this study, the pain was defined as greater than 3 on the scale, considered to potentially affect emotional or physical functioning [20]. Postoperative complications (such as anastomosis or intraabdominal bleeding, anastomosis leakage, abdominal cavity abscess, wound problems, intestinal obstruction, lymphatic leakage, cardiac disease, deep vein thrombosis, and pulmonary disease) were assessed through clinical manifestations, laboratory examination results, ultrasonography reports, and imaging findings. Furthermore, massive hemorrhage was defined as an amount of at least $300 \mathrm{ml}$. Patients with albumin levels below 30g/L were defined as hypoproteinemia.

\section{Inclusion criteria}

The inclusion criteria were showed as follows: (1) age between 18 and 75 years; (2) pathologically diagnosed as colorectal carcinoma; (3) TNM stages II-III, diagnosed through postoperative pathology; and (4) patients underwent colorectal R0 resection.

\section{Exclusion criteria}

The following exclusion criteria applied to patients in this research are (1) previous history of other systemic malignancies; (2) patients of familial adenomatous polyposis or human nonpolyposis CRC; (3) severe respiratory tract, liver, kidney, or cardiovascular disease; (4) the patients going through emergency surgery; and (5) the patients whose information cannot be collected accurately.

\section{Surgical procedure}

Bowel preparation was performed by taking sulfate-free polyethylene glycol electrolyte powder orally 1 day before surgery. A standardized R0 surgical resection of colorectal carcinoma was then performed, and all surgical procedures were conducted with strict adherence to the National Ministry of Colorectal Cancer diagnosis and treatment standards. Different procedures were selected according to the location of carcinomas. Laparotomy or laparoscopy was chosen according to intraoperative findings. Peritoneal lavage, as an important procedure was normally performed using $1000 \mathrm{ml} 0.9 \%$ saline solution after intestinal anastomosis, which was then absorbed completely. Finally, the excised specimen was sent to professional pathologists to identify the TNM stage.

\section{IOC}

Lobaplatin was used for patients who underwent intraoperative intraperitoneal chemotherapy. Fifty milligrams of lobaplatin was dissolved in $500 \mathrm{ml} 0.9 \%$ saline solution (SS) at a concentration of $0.1 \mathrm{~g} / \mathrm{L}$. The solution was then injected into an abdominal cavity through the drainage tube after the abdominal incision or laparoscopic port was closed. Vibrating abdomen adequately was routinely performed to make mixed solution distributing in the abdominal cavity evenly as far as possible. Finally, the mixed solution was discharged from abdominal cavity $5 \mathrm{~h}$ later. In the meanwhile, the drainage tube is closed to prevent the efflux of abdominal chemotherapy drugs. And whether patients received IOC is up to themselves or their family members before operative.

\section{Statistical analysis}

The study was designed to evaluate the superiority in terms of disease-free survival (DFS) of combining radical surgery and IOC compared with surgery without IOC. Survival curves were created using the Kaplan-Meier method, and the differences between the two groups were compared using $t$ texts and $\mathrm{X}^{2}$ tests. Multivariate analyses were evaluated with Cox proportional hazards models. All $P$ values calculated in the analysis were 2sided, and $P$ values less than 0.05 were considered statistically significant. Statistical analyses were performed using SPSS software, version 26.0 (IBM Corporation).

\section{Results}

From June 1, 2017, to December 31, 2018, a total of 755 patients who underwent radical surgery for colorectal carcinoma in The Second Affiliated Hospital of Jilin University were collected, of which 537 cases were selected to further assessed ulteriorly according to the inclusion criteria. And 146 cases were excluded according to exclusion criteria (including 9 patients with previous history of other systemic malignancies; 2 patients with familial adenomatous polyposis; 8 patients undergoing emergency surgery; 4 patients with serious respiratory tract, liver, kidney, or cardiovascular disease; and 123 patients' medical records unavailable) (Fig. 1). 391 cases were eventually enrolled in the present study eventually, with 220 patients assigned contents for the surgery without IOC group, and 171 assigned to the surgery plus IOC group. 


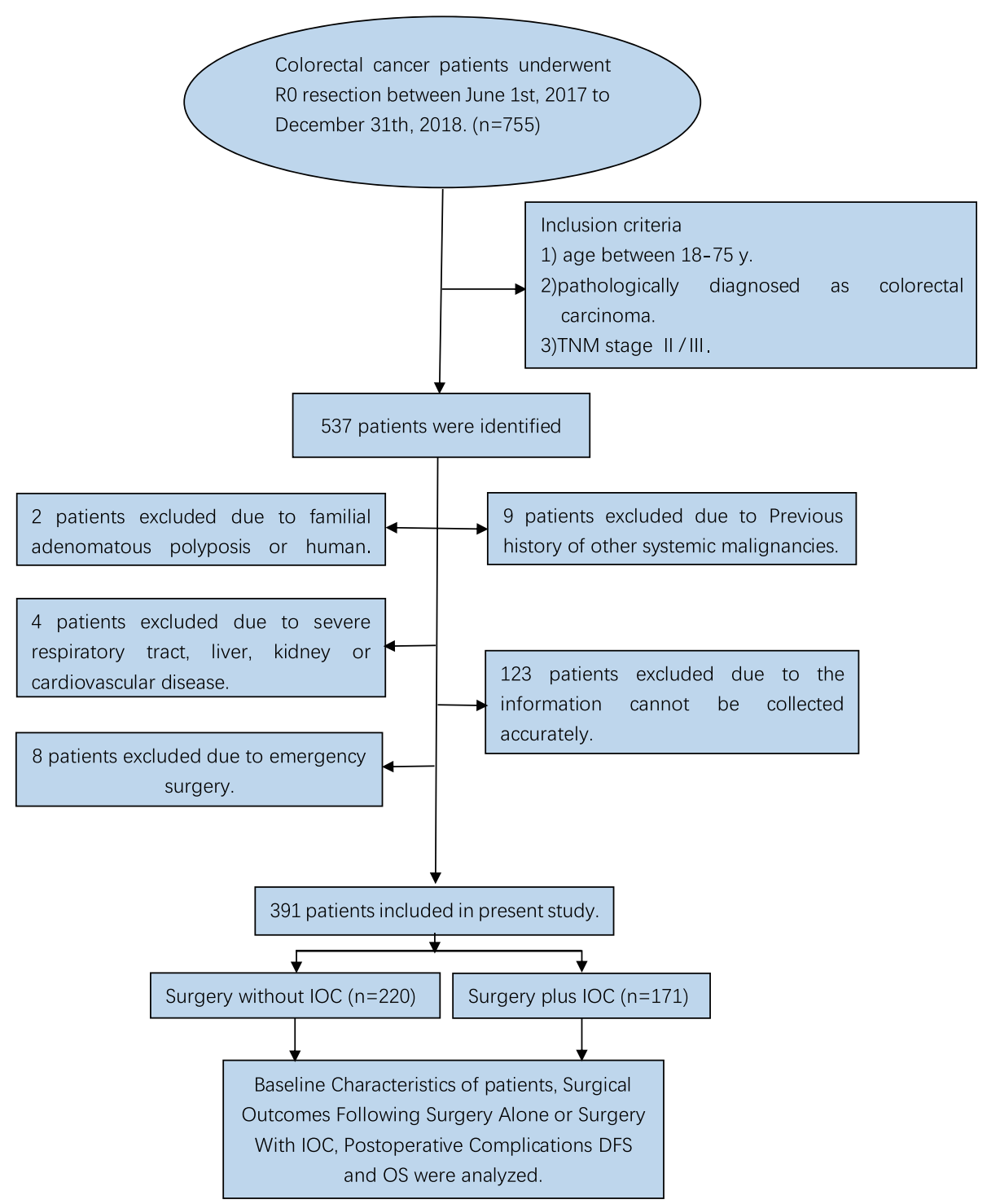

Fig. 1 CONSORT diagram of patient flow

The present research included 391 patients (251 men and 140 women) who underwent surgery without IOC $(n=171)$ or surgery plus IOC $(n=220)$, with a mean (SD) age of 60.4 (9.7) years in the surgery without IOC group and $60.6(8.7)$ in the surgery plus IOC group $(P=$ $.85)$. Table 1 demonstrated that there was no statistical difference in the baseline clinical characteristics of the 391 patients between the two groups.

Surgery-related information is presented in Table 2 . Laparoscopy surgeries were performed in a large proportion of patients (79.0\%), 172 laparoscopy operations and 48 open surgeries were performed in the surgery without IOC group, and 137 laparoscopy operations and 34 open surgeries were performed in combining surgery and IOC group. No significant differences were observed between groups in operation methods, ASA stage, operation time, and amount of intraoperation bleeding. Compared with the group of 171 patients receiving surgery without IOC, the group of 220 patients undergoing surgery plus IOC showed a similar trend in terms of time to first flatus (72.6[10.4] vs 72.8[9.7]; difference, -0.2 ; $95 \% \mathrm{CI},-2.2-1.8$; $P=.82)$, LOS (19.2[6.4] vs 18.6[5.3]; difference, 0.6; 95\%CI, $-0.6-1.8 ; P=.32$ ), and postoperative laboratory results.

No perioperative deaths occurred both in the surgery without IOC group and the surgery plus IOC group (Table 3). No difference in abdominal pain was witnessed between the surgery without IOC group (84 of 220 patients [38.2\%]) and surgery combined IOC group (74 of 171 patients [43.3\%]) (difference, $-5.1 \% ; P=.31$ ), nor in hypoproteinemia, anastomosis or intra-abdominal bleeding, anastomosis leakage, abdominal cavity abscess, wound problems, intestinal obstruction, cardiac disease, 
Table 1 Baseline characteristics of patients

\begin{tabular}{|c|c|c|c|}
\hline Characteristic & $\begin{array}{l}\text { Patients, no. } \\
\text { Surgery } \\
\text { without IOC } \\
(N=220)\end{array}$ & $\begin{array}{l}\text { Surgery } \\
\text { plus IOC } \\
(N=171)\end{array}$ & $P$ value \\
\hline Age, mean (SD), y & $60.4(9.7)$ & $60.6(8.7)$ & .85 \\
\hline \multicolumn{4}{|l|}{ Sex } \\
\hline Male & 137 & 114 & \multirow[t]{2}{*}{.37} \\
\hline Female & 83 & 57 & \\
\hline \multicolumn{4}{|l|}{ Hypertension } \\
\hline Yes & 57 & 49 & \multirow[t]{2}{*}{.55} \\
\hline No & 163 & 122 & \\
\hline \multicolumn{4}{|l|}{ Diabetic mellitus } \\
\hline Yes & 38 & 30 & \multirow[t]{2}{*}{.94} \\
\hline No & 182 & 141 & \\
\hline CEA, mean (SD), ng/mL & $8.41(14.90)$ & $9.07(15.41)$ & .67 \\
\hline \multicolumn{4}{|l|}{ Tumor location } \\
\hline Right colon & 64 & 39 & \multirow[t]{3}{*}{.37} \\
\hline Left colon & 48 & 40 & \\
\hline Rectal & 108 & 92 & \\
\hline Tumor size, mean (SD), cm & $4.8(1.6)$ & 4.6(1.7) & .42 \\
\hline \multicolumn{4}{|l|}{ Pathologic T category } \\
\hline $\mathrm{T} 1$ & 4 & 3 & \multirow[t]{4}{*}{.84} \\
\hline $\mathrm{T} 2$ & 8 & 9 & \\
\hline $\mathrm{T} 3$ & 195 & 147 & \\
\hline T4 & 13 & 12 & \\
\hline \multicolumn{4}{|l|}{ Pathologic $N$ category } \\
\hline No & 96 & 80 & \multirow[t]{3}{*}{.76} \\
\hline $\mathrm{N} 1$ & 93 & 66 & \\
\hline N2 & 31 & 25 & \\
\hline \multicolumn{4}{|l|}{ TNM stage } \\
\hline$\|$ & 96 & 80 & \multirow[t]{2}{*}{.54} \\
\hline III & 124 & 91 & \\
\hline \multicolumn{4}{|l|}{ Differentiation } \\
\hline Well & 6 & 4 & \multirow[t]{3}{*}{.44} \\
\hline Moderate & 204 & 154 & \\
\hline Poor & 10 & 13 & \\
\hline \multicolumn{4}{|l|}{ Pathological type } \\
\hline Tubular adenocarcinoma & 209 & 159 & \multirow[t]{3}{*}{.12} \\
\hline Mucinous adenocarcinoma & 7 & 3 & \\
\hline Mixed adenocarcinoma & 4 & 9 & \\
\hline \multicolumn{4}{|l|}{ Vascular invasion } \\
\hline Yes & 86 & 65 & \multirow[t]{2}{*}{.83} \\
\hline No & 134 & 106 & \\
\hline \multicolumn{4}{|l|}{ Postoperative chemotherapy } \\
\hline Yes & 122 & 92 & \multirow[t]{2}{*}{.75} \\
\hline No & 98 & 79 & \\
\hline
\end{tabular}

Abbreviation: IOC Intraoperative intraperitoneal chemotherapy deep vein thrombosis, or pulmonary disease. ClavienDindo classification [21] was used to assess the severity of postoperative complications. There was no significant difference between two groups in I/II stage complications (106 [48.2\%] vs 84[49.1\%]; difference, $-0.9 \% ; P=$ $.85)$ or III/IV stage complications (20[9.1\%)] vs $11[6.4]$; difference, $2.7 \% ; P=.34$ ).

To determine whether IOC was independent prognostic factor associated with CRC clinical outcomes, a univariate and multivariate analysis was performed using the Cox proportional hazard model (Table 4). The risk variables included age, gender, tumor location, tumor size, pathological $N$ stage, differentiation, vascular invasion, ASA stage, TNM stage, IOC, and POC. These factors were generally considered to be associated with prognosis of CRC. In the univariate analysis, IOC (HR 0.53 , 95\%CI 0.32-0.86, $P=.01$ ), pathologic $N$ stage (HR 2.12, 95\%CI 1.24-3.61, $P=.006$ ), and TNM stage (HR 226 , 95\%CI $1.37-3.73, P=.002)$ were significantly associated with survival, while vascular invasion, gender, age, tumor size, tumor location, POC, and ASA stage were not. However, POC and vascular invasion were considered worthy of further study because of the $P$ values of which were approximate to 0.05 . In the final multivariate Cox regression model, IOC and POC independent of other factors was associated with a favor prognosis in CRC patients with stage II/III (HR 0.50, 95\%CI 0.30 $0.82, P=.006$; HR $0.53,95 \%$ CI $0.33-0.85, P=.009$ ).

In the present study, 75 patients had experienced a relapse or dead (surgery without IOC group, $N=53$; surgery plus IOC group, $N=23$ ). To further analyze the association of IOC and prognosis in patients with CRC, Kaplan-Meier analyses were performed. Considering the effect of prognosis with postoperative adjuvant chemotherapy (POC) in treating advanced colorectal carcinoma, POC was analyzed in the study. The POC regimens were mainly cisplatin combined with fluorouracil. The association between DFS and IOC was showed in Fig. 2. The survivorship analysis (KaplanMeier) showed a $83.2 \%$ DFS rate in IOC group and a $74 \%$ DFS rate in control group after 3 years $(P=.012$, Kaplan-Meier log-rank), and IOC was also associated with a favorable prognosis in patients underwent POC $(P=.014$, Kaplan-Meier log-rank). In patients with stage II colorectal carcinoma, DFS did not differ between two groups $(P=.553$, Kaplan-Meier log-rank), nor in patients accepted POC $(P=.453$, Kaplan-Meier log-rank). In stage III CRC patients, the estimated DFS rate for patients receiving IOC was $82.2 \%$ and patients without IOC was $66.4 \%$ after 3 years, which demonstrated that IOC was associated with a favorable prognosis in stage III patients $(P=.012$, Kaplan-Meier log-rank). Furthermore, the differences were still remained between the two groups when considering the influence about postoperative 
Table 2 Surgical outcomes following surgery without IOC or surgery with IOC

\begin{tabular}{|c|c|c|c|c|}
\hline Outcome & $\begin{array}{l}\text { Mean (SD) values } \\
\text { surgery without IOC } \\
(N=220)\end{array}$ & $\begin{array}{l}\text { Surgery plus } I O C \\
(N=171)\end{array}$ & $\begin{array}{l}\text { Between-group difference } \\
(95 \% \mathrm{Cl})\end{array}$ & $P$ value \\
\hline \multicolumn{5}{|l|}{ Operation method, no. (\%) } \\
\hline Laparoscopy & 172(78.1) & 137(80.1) & & .64 \\
\hline Open surgery & $48(21.9)$ & 34(19.9) & & \\
\hline \multicolumn{5}{|l|}{ ASA } \\
\hline$\|$ & 123(55.9) & $98(57.3)$ & & .92 \\
\hline III & $95(43.2)$ & $71(41.5)$ & & \\
\hline IV & $2(0.9)$ & $2(1.2)$ & & \\
\hline Operation time, min & $212.6(54.2)$ & $211.6(46.2)$ & $0.96(-9.30$ to 11.16$)$ & .85 \\
\hline Amount of intraoperation bleeding, $\mathrm{ml}$ & 113(58) & $114(47)$ & $-0.3(-11.0$ to 10.5$)$ & .96 \\
\hline Time to first flatus, hour & $72.6(10.4)$ & $72.8(9.7)$ & $-0.2(-2.2$ to 1.8$)$ & .82 \\
\hline LOS, day & $19.2(6.4)$ & 18.6(5.3) & $0.6(-0.6$ to 1.8$)$ & .32 \\
\hline \multicolumn{5}{|l|}{ Postoperative laboratory results } \\
\hline White blood cell count, $\times 109 / \mathrm{L}$ & $10.68(2.67)$ & $10.39(2.53)$ & $0.30(-0.23$ to 0.81$)$ & .28 \\
\hline Neutrophil count, $\times 109 / L$ & $8.81(2.76)$ & $8.57(2.52)$ & $0.25(-0.28$ to 0.78$)$ & .36 \\
\hline Neutrophil ratio & $0.819(0.073)$ & $0.817(0.079)$ & $0.002(-0.014$ to 0.017$)$ & .83 \\
\hline Hemoglobin, g/L & $119(17)$ & $119(21)$ & $0.6(-3.2$ to 4.4$)$ & .75 \\
\hline Albumin, g/L & $33.5(3.2)$ & $33.7(3.1)$ & $-0.2(-0.8$ to 0.5$)$ & .58 \\
\hline Albumin globulin ratio & $1.36(0.18)$ & $1.38(0.21)$ & $-0.03(-0.06$ to 0.01$)$ & .20 \\
\hline
\end{tabular}

Abbreviation: IOC Intraoperative intraperitoneal chemotherapy, ASA American Society of Anesthesiologists, LOS Long of stay

Table 3 Postoperative complications

\begin{tabular}{|c|c|c|c|}
\hline Complication & $\begin{array}{l}\text { Patients, } \\
\text { no. }(\%) \\
\text { Surgery } \\
\text { without IOC } \\
(N=220)\end{array}$ & $\begin{array}{l}\text { Surgery } \\
\text { plus IOC } \\
(N=171)\end{array}$ & $\begin{array}{l}P \\
\text { value }\end{array}$ \\
\hline Abdominal pain & $84(38.2)$ & $74(43.3)$ & .31 \\
\hline Hypoproteinemia & $32(14.5)$ & $20(11.7)$ & .41 \\
\hline $\begin{array}{l}\text { Anastomosis or intra-abdominal } \\
\text { bleeding }\end{array}$ & $2(0.9)$ & $1(0.6)$ & .71 \\
\hline $\begin{array}{l}\text { Anastomosis leakage } \\
\text { Abdominal cavity abscess }\end{array}$ & $\begin{array}{l}9(4.1) \\
7(3.2)\end{array}$ & $\begin{array}{l}3(1.8) \\
2(1.2)\end{array}$ & $\begin{array}{l}.18 \\
.18\end{array}$ \\
\hline Wound problems & 24(10.9) & 18(10.5) & .90 \\
\hline Intestinal obstruction & $4(1.8)$ & $3(1.8)$ & .92 \\
\hline Cardiac disease & $7(3.2)$ & $8(4.7)$ & .45 \\
\hline Deep vein thrombosis & $4(1.8)$ & $3(1.8)$ & .96 \\
\hline Pulmonary disease & $11(5.0)$ & $9(5.3)$ & .90 \\
\hline \multicolumn{4}{|l|}{ Clavien-Dindo classification $^{a}$} \\
\hline$|/| \mid$ & 106(48.2) & $84(49.1)$ & .85 \\
\hline III/IV & 20(9.1) & $11(6.4)$ & .34 \\
\hline V & 0 & 0 & \\
\hline
\end{tabular}

Abbreviation: IOC Intraoperative intraperitoneal chemotherapy. ${ }^{\text {aThe Clavien- }}$ Dindo classification scheme is explained in Dindo et al. [21] chemotherapy $\quad(P=.014, \quad$ Kaplan-Meier log-rank). Moreover, the association of OS and IOC was shown in Fig. 3. Patients who underwent IOC perform a better prognosis than control group in stage II and III patients $(P=.022$, Kaplan-Meier log-rank), so did patients accept IOC combined POC ( $P=.005$, Kaplan-Meier log-rank). In patients with stage II, IOC did not seem to make any sense to promote a better prognosis, neither they accept POC $(P=.512$, Kaplan-Meier log-rank) or not $(P=.453$, Kaplan-Meier log-rank). However, in patients with stage III, IOC can significantly improve patients' overall survival whether they get treatment with POC $(P=.025$, Kaplan-Meier log-rank $) \quad(P=.006$, Kaplan-Meier logrank).

\section{Discussion}

In recent years, the prognosis for colorectal cancer (CRC) performs more and more favorable with the development of diagnostic and treatment measures. However, the recurrence rate of patients who underwent curative resection for colorectal carcinoma was as high as $29.9 \%$ [22]. And peritoneal metastasis from colorectal cancer tended to perform an extremely poor prognosis. Remarkably, one survey revealed that the prognosis of the single-organ metastasis in the peritoneum group was even as poor as that of the multiple-organ metastases group [6]. 
Table 4 Univariate and multivariate associations between covariates and the composite primary endpoint of recurrence or dead in CRC patients with stage II/II

\begin{tabular}{|c|c|c|c|c|}
\hline \multirow[t]{2}{*}{ Characteristic } & \multicolumn{2}{|c|}{ Univariate analysis } & \multicolumn{2}{|c|}{ Multivariate analysis } \\
\hline & HR (95\% Cl) & $P$ value & $\mathrm{HR}(95 \% \mathrm{Cl})$ & $P$ value \\
\hline \multicolumn{5}{|l|}{$\mathrm{IOC}$} \\
\hline Did not receive & 1.0 (reference) & & 1.0(reference) & \\
\hline Received & $0.53(0.32-0.86)$ & .01 & $0.50(0.30-0.82)$ & .006 \\
\hline \multicolumn{5}{|l|}{ Gender } \\
\hline Female & 1.0(reference) & & 1.0(reference) & \\
\hline Male & $1.31(0.80-2.13)$ & .29 & $1.37(0.83-2.27)$ & .22 \\
\hline \multicolumn{5}{|l|}{ Age } \\
\hline$<50$ & 1.0(reference) & & 1.0(reference) & \\
\hline$\geq 50$ & $1.54(0.71-3.34)$ & .28 & $1.50(0.67-3.32)$ & .33 \\
\hline \multicolumn{5}{|l|}{ Tumor location } \\
\hline Right colon & 1.0(reference) & & 1.0(reference) & \\
\hline Left colon & $1.42(0.75-2.69)$ & .28 & $1.33(0.68-2.59)$ & .40 \\
\hline Rectal & $1.11(0.63-1.95)$ & .71 & $0.92(0.51-1.66)$ & .78 \\
\hline \multicolumn{5}{|l|}{ Tumor size } \\
\hline$<5 \mathrm{~cm}$ & 1.0(reference) & & 1.0(reference) & \\
\hline$\geq 5 \mathrm{~cm}$ & $1.01(0.64-1.58)$ & .97 & $1.13(0.70-1.81)$ & 62 \\
\hline \multicolumn{5}{|c|}{ Pathologic $N$ category } \\
\hline No & 1.0(reference) & & 1.0(reference) & \\
\hline N1 & $2.12(1.24-3.61)$ & .006 & $2.23(1.23-4.05)$ & .008 \\
\hline N2 & $2.64(1.39-5.00)$ & .003 & $2.84(1.37-5.88)$ & .005 \\
\hline \multicolumn{5}{|l|}{ TNM stage } \\
\hline$\|$ & 1.0(reference) & & 1.0(reference) & \\
\hline III & $2.26(1.37-3.73)$ & .002 & $2.37(1.33-4.20)$ & .003 \\
\hline \multicolumn{5}{|l|}{ Differentiation } \\
\hline Well & 1.0(reference) & & 1.0(reference) & \\
\hline Moderate & $0.88(0.22-3.59)$ & .86 & $0.44(0.10-1.94)$ & .28 \\
\hline Poor & $0.80(0.15-4.38)$ & .80 & $0.33(0.05-2.05)$ & .24 \\
\hline \multicolumn{5}{|l|}{ Vascular invasion } \\
\hline No & 1.0(reference) & & 1.0(reference) & \\
\hline Yes & $1.55(0.99-2.43)$ & .06 & $1.34(0.81-2.22)$ & .26 \\
\hline \multicolumn{5}{|l|}{ ASA } \\
\hline$\|$ & 1.0(reference) & & 1.0(reference) & \\
\hline III/IV & $1.29(0.83-2.03)$ & .26 & $1.54(0.96-2.49)$ & .07 \\
\hline \multicolumn{5}{|l|}{ POC } \\
\hline Did not receive & 1.0(reference) & & 1.0(reference) & \\
\hline Received & $0.66(0.42-1.04)$ & .07 & $0.53(0.33-0.85)$ & .009 \\
\hline
\end{tabular}

Abbreviation: IOC Intraoperative intraperitoneal chemotherapy, ASA American Society of Anesthesiologists

Locally advanced colorectal cancer surgery, it should be noted, increases the risk of peritoneal metastasis because of the lymphatic opening caused by lymphatic clearance [8]. Therefore, if intraoperative intraperitoneal chemotherapy is put into effect, the viable malignancy cells resulting from destroyed lymphatic vessels may be eradicated and the prognosis would be better.

Here, we describe two main findings. First, when the lobaplatin concentration is $0.1 \mathrm{~g} / \mathrm{L}$, there is no significant difference between the intraoperative intraperitoneal chemotherapy group and the control group in shortterm complications rate. Second, whether the IOC group is superior to the control group depends on the stage of CRC. For stage II CRC patients, there were no distinct differences between the two groups in the terms of disease-free survival (DFS) and overall survival (OS); on the contrary, for stage III CRC patients, the IOC group has significant advantages both in disease-free survival (DFS) and overall survival (OS).

Several randomized prospective studies $[12,23]$ that evaluated the effect and safety of hyperthermic intraperitoneal chemotherapy (HIPC) as a therapy for peritoneal metastatic (PM) carcinoma have been published over recent decades. However, studies related to intraperitoneal chemotherapy during operation for CRC patients without PM are quite rare.

There are two literatures that evaluate the short-term efficacy of IOC in CRC patients. The study of the shortterm effect analysis of intraoperative intraperitoneal perfusion chemotherapy with lobaplatin for colorectal cancer indicated that there is no distinction on short-term recovery between the study group and control group in patients with $\mathrm{CRC}$, which was consistent with the result in the present study. However, Wang et al. indicated intraoperative intraperitoneal chemotherapy increases the incidence of anastomotic leakage after anterior resection of rectal tumors [24]. The lobaplatin concentration in Wang's research was $0.12 \mathrm{~g} / \mathrm{L}$, which was higher than that in the present study, which may be the reason for the difference. Further studies are needed to verify whether IOC has an impact on postoperative anastomotic fistula for rectal malignant tumors. Moreover, one retrospective study evaluated the overall survival (OS) in CRC patients undergoing IOC. The research of intraoperative chemotherapy with a Novel Regimen Improved the Therapeutic Outcomes of Colorectal Cancer enrolled 551 CRC patients, of which 193 patients underwent IOC. There was no significant difference in complication rate and mortality between the two groups, but the IOC group presented a better prognosis in phase II and III CRC patients compared with the control group. Those results were basically consistent with the result in the present research. However, in the present study, we found there would be no significant difference between the two groups in terms of prognosis if the CRC patients were at stage II. The difference may result from the earlier $\mathrm{T}$ stage of patient in the present study. Of 182 stage 


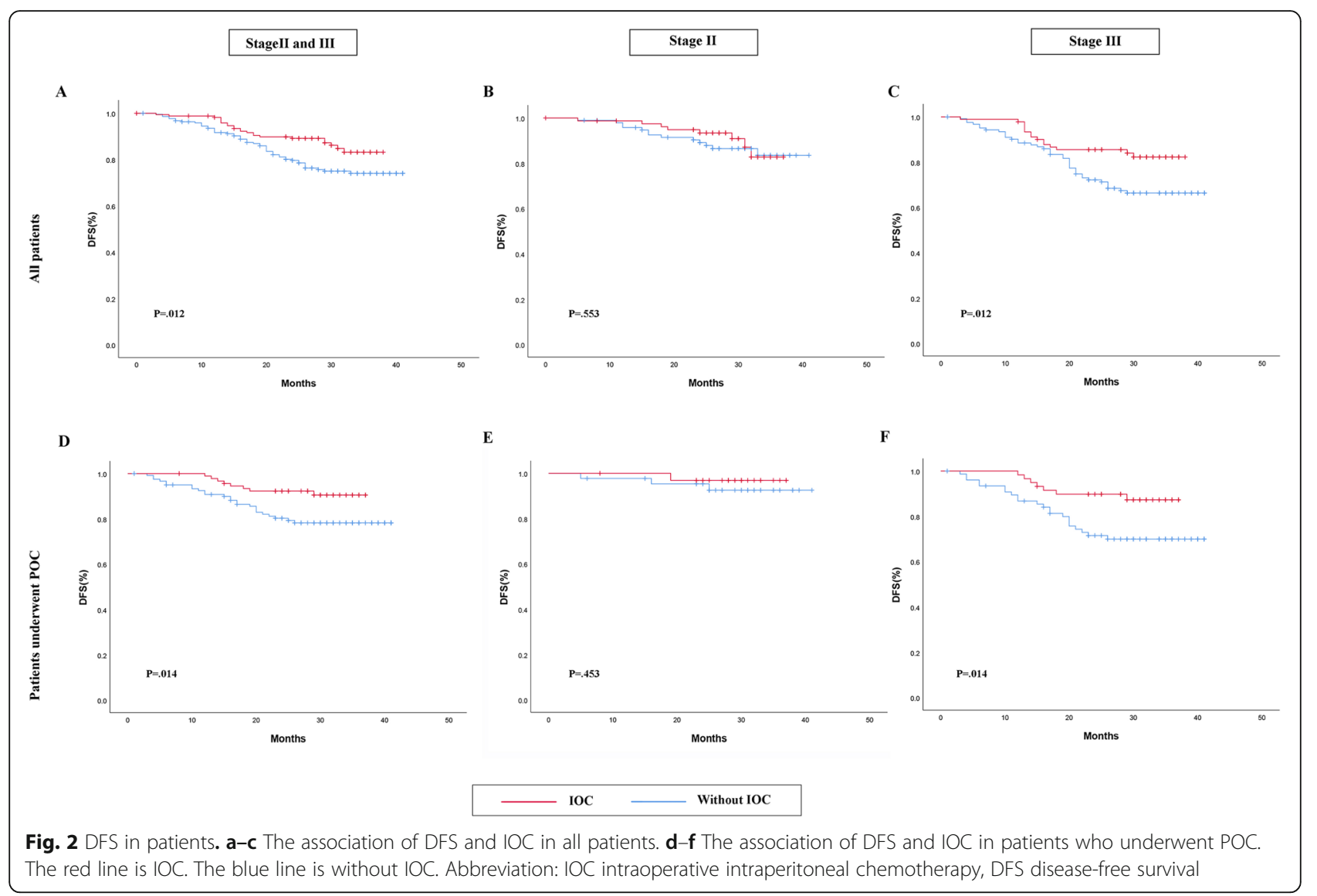

II CRC patients, 174 (95.6\%) patients were at T3 stage, and only 8 (4.4) patients were at T4 stage. Leung et al. presented that T4 stage identifies the majority of CRC patients who later develop PM [25]. Furthermore, in a prospective evaluation of the prognostic importance of peritoneal involvement in colonic cancer, Shepherd et al. enrolled 412 colorectal malignant tumor patients who underwent a primary resection and concluded that local peritoneal involvement is an independent predictive factor for intraperitoneal recurrence [26]. In addition, Jayne et al. found that 349 of 3019 patients with CRC have synchronous or metachronous PM, with $19 \%$ of the metachronous PM existing serosal invasion (stage T4) [5]. Therefore, intraoperative intraperitoneal chemotherapy should be recommended in patients with pT4 colorectal cancer. But further study was needed to demonstrate the effectiveness of IOC for T4 stage patients.

In the present study, lobaplatin was used for interoperative intraperitoneal chemotherapy. Lobaplatin, as a new generation platinum compound, has the same inhibitory effect on CRC cells as oxaliplatin [27]. In addition, lobaplatin is appropriate for intraoperative intraperitoneal chemotherapy due to its lighter inhibitory effects on the neurological system, hematological system, and gastrointestinal system. A preclinical model research [16] conduct that the survival rate of suspended CRC cells was only $16.3 \%$ when treated with $100 \mathrm{mg} / \mathrm{L}$ lobaplatin for $6 \mathrm{~h}$. Therefore, $0.1 \mathrm{~g} / \mathrm{L}$ lobaplatin intraperitoneal chemotherapy for $6 \mathrm{~h}$ during surgery was performed in order to obtain a strong efficacy on CRC patients with suspicious PM in the present study, while the dosage of $50 \mathrm{mg} /$ person was far lower than the recommended dosage $\left(50 \mathrm{mg} / \mathrm{m}^{2}\right)$, without any obvious toxic side reaction.

The present study had several limitations. First, this is a retrospective comparison, unobserved confounders remained. An RCT would be idealized. Second, a sample size of the retrospective study was still small because the duration of implementing intraperitoneal perfusion chemotherapy was less than 5 years in The Second Affiliated Hospital of Jilin University. But the study with a sample size of 391 patients was also acceptable. Third, our study involved only a Chinese population at a single center. Fours, there was no differences in the dosage of lobaplatin between CRC patients. Therefore, an individual chemotherapy regimen calculated by peritoneal area should be put forward through further study, though $50 \mathrm{mg} / \mathrm{L}$ lobaplatin had been confirmed safe and 


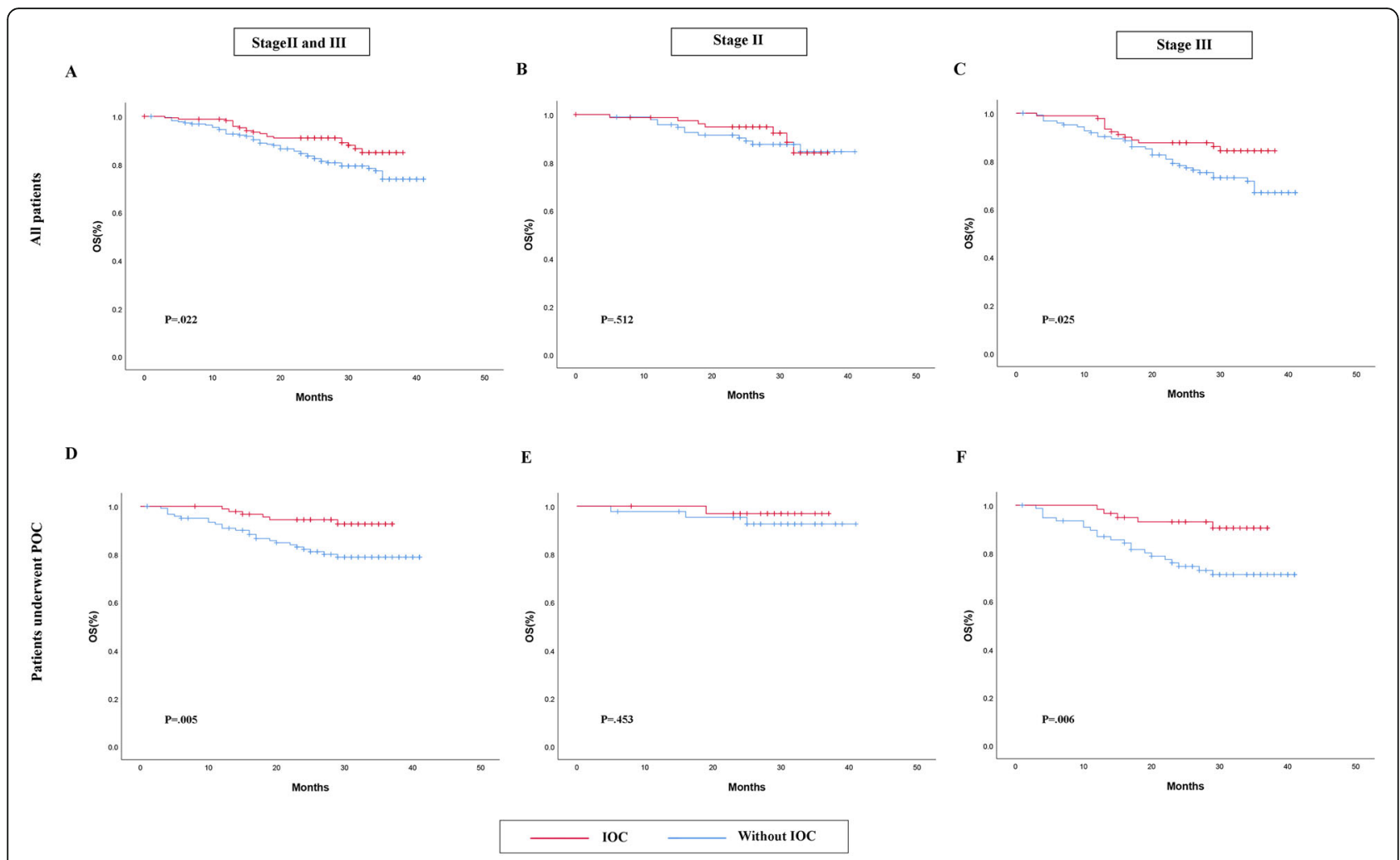

Fig. 3 OS in patients. a-c The association of OS and IOC in all patients. d-f The association of OS and IOC in patients who underwent POC. The red line is IOC. The blue line is without IOC. Abbreviation: IOC intraoperative intraperitoneal chemotherapy, OS overall survival

effective. In addition, a prospective and multi-center study with a large sample size is required in the future.

\section{Conclusion}

To our knowledge, only one study reported that IOC significantly improved the prognosis of colorectal cancer so far. In the present study, we found that surgery plus IOC generate a favorable prognosis for stage III CRC patients but not stage II without any side-effects when the dosage of lobaplatin was $0.1 \mathrm{~g} / \mathrm{L}$. As a new, safe, and simple procedure, IOC therapy can be performed at most hospitals and does not require any special devices or techniques. Thus, IOC is a promising and exciting therapeutic strategy for patients with CRC.

\section{Abbreviations}

IOC: Intraoperative intraperitoneal chemotherapy; POC: Postoperative adjuvant chemotherapy; CEA: Carcinoembryonic antigen; CRC: Colorectal cancer; DFS: Disease-free survival; CRS: Cytoreductive surgery; HIPE C: Hyperthermic intraperitoneal chemotherapy; OS: Overall survival; LOS: Length of stay; VAS: Visual analogue scale/score; SS: Saline solution; ASA: American society of anesthesiologists; PM: Peritoneal metastatic; PFCCs: Peritoneal-free cancer cells

\section{Acknowledgements}

None.

\section{Authors' contributions}

AS and MW conceived the study design. SW, YY, and LL acquired the data for the study. ZZ, DL, and YG analyzed and interpreted the data. AS drafted the manuscript. SW and $Y Y$ revised the manuscript critically. The authors read and approved the final manuscript.

Funding

This study was not funded by any outside source.

Availability of data and materials

The datasets generated and analyzed during the current study available from the corresponding author on reasonable request.

\section{Declarations}

Ethics approval and consent to participate

The study protocol was approved by the institutional review board of The Second Hospital of Jilin University. Due to the retrospective design of the study, the local ethic committee confirmed that informed consent was not necessary from participants. The demand of patient informed consent was deserted because of the retrospective nature of this study.

\section{Consent for publication}

Not applicable.

\section{Competing interests}

The authors declare that they have no competing interests

\section{Author details}

'Colorectal Section, Department of Surgery, The Second Hospital of Jilin University, No. 218, Ziqiang Dist, Changchun 130041, Jilin, China. 2Department of Dermatology The Second Hospital of Jilin University, No. 218, Ziqiang Dist, Changchun 130041, Jilin, China. ${ }^{3}$ Department of Hematology and Oncology, The Second Hospital of Jilin University, No. 218, Ziqiang Dist, Changchun 130041, Jilin, China. 
Received: 5 January 2021 Accepted: 16 March 2021

Published online: 22 March 2021

\section{References}

1. Jemal A, Siegel R, Ward E, et al. Cancer statistics, 2008. CA Cancer J Clin. 2008;58(2):71-96. https://doi.org/10.3322/ca.2007.0010 published Online First: Epub Date.

2. Arnold M, Sierra MS, Laversanne M, Soerjomataram I, Jemal A, Bray F. Global patterns and trends in colorectal cancer incidence and mortality. Gut. 2017; 66(4):683-91. https://doi.org/10.1136/gutjnl-2015-310912 published Online First: Epub Date.

3. Lan YT, Chang SC, Yang SH, et al. Comparison of clinicopathological characteristics and prognosis between early and late recurrence after curative surgery for colorectal cancer. Am J Surg. 2014;207(6):922-30 https://doi.org/10.1016/j.amjsurg.2013.08.035 published Online First: Epub Date.

4. Sluiter NR, Rovers KP, Salhi Y, et al. Metachronous peritoneal metastases after adjuvant chemotherapy are associated with poor outcome after cytoreduction and HIPEC. Ann Surg Oncol. 2018;25(8):2347-56. https://doi. org/10.1245/s10434-018-6539-x published Online First: Epub Date.

5. Jayne DG, Fook S, Loi C, Seow-Choen F. Peritoneal carcinomatosis from colorectal cancer. Br J Surg. 2002;89(12):1545-50. https://doi.org/10.1046/j.13 65-2168.2002.02274.x published Online First: Epub Date.

6. Arakawa K, Kawai K, Ishihara S, et al. Prognostic significance of peritoneal metastasis in stage IV colorectal cancer patients with RO resection: a multicenter, retrospective study. Dis Colon Rectum. 2017; 60(10):1041-9. https://doi.org/10.1097/dcr.0000000000000858 published Online First: Epub Date.

7. Alyami M, Hübner M, Grass F, et al. Pressurised intraperitoneal aerosol chemotherapy: rationale, evidence, and potential indications. Lancet Oncol. 2019;20(7):e368-e77. https://doi.org/10.1016/s1470-2045(19)30318-3 published Online First: Epub Date.

8. Marutsuka T, Shimada S, Shiomori K, Hayashi N, Yagi Y, Yamane T, Ogawa M. Mechanisms of peritoneal metastasis after operation for non-serosainvasive gastric carcinoma: an ultrarapid detection system for intraperitoneal free cancer cells and a prophylactic strategy for peritoneal metastasis. Clin Cancer Res. 2003;9(2):678-85.

9. Kuramoto M, Shimada S, Ikeshima $\mathrm{S}$, et al. A proposal of a practical and optimal prophylactic strategy for peritoneal recurrence. J Oncol. 2012; 2012:340380. https://doi.org/10.1155/2012/340380 published Online First: Epub Date.

10. Glehen O, Osinsky D, Beaujard AC, Gilly FN. Natural history of peritoneal carcinomatosis from nongynecologic malignancies. Surg Oncol Clin N Am 2003;12(3):729-739, xiii doi: https://doi.org/10.1016/s1055-3207(03)000449 [published Online First: Epub Date].

11. Tonello M, Sommariva A, Pirozzolo G, Mattara G, Pilati P, et al. Eur J Surg Oncol. 2019;45(11):2003-8. https://doi.org/10.1016/j.ejso.2019.06.020 published Online First: Epub Date.

12. Aarts F, Bleichrodt RP, de Man B, Lomme R, Boerman OC, Hendriks T. The effects of adjuvant experimental radioimmunotherapy and hyperthermic intraperitoneal chemotherapy on intestinal and abdominal healing after cytoreductive surgery for peritoneal carcinomatosis in the rat. Ann Surg Oncol. 2008;15(11):3299-307. https://doi.org/10.1245/s10434-008-0070-4 published Online First: Epub Date.

13. Aarts F, Hendriks T, Boerman OC, Koppe MJ, Oyen WJ, Bleichrodt RP. A comparison between radioimmunotherapy and hyperthermic intraperitoneal chemotherapy for the treatment of peritoneal carcinomatosis of colonic origin in rats. Ann Surg Oncol. 2007;14(11): 3274-82. https://doi.org/10.1245/s10434-007-9509-2 published Online First: Epub Date.

14. Wu X, Tang P, Li S, et al. A randomized and open-label phase II tria reports the efficacy of neoadjuvant lobaplatin in breast cancer. Nat Commun. 2018;9(1):832. https://doi.org/10.1038/s41467-018-03210-2 published Online First: Epub Date.

15. Yu J, Li S, Qi J, et al. Cleavage of GSDME by caspase-3 determines lobaplatin-induced pyroptosis in colon cancer cells. Cell Death Dis. 2019; 10(3):193. https://doi.org/10.1038/s41419-019-1441-4 published Online First: Epub Date.

16. Shan L, Bai B, Lv Y, Xie B, Huang X, Zhu H. Lobaplatin suppresses proliferation and peritoneal metastasis of colorectal cancer in a preclinical model. Biomed Pharmacother. 2018;108:486-91. https://doi.org/10.1016/j. biopha.2018.09.063 published Online First: Epub Date.

17. Zhou HT, Jiang J, Guan X, et al. The short-term effect analysis of intraoperative intraperitoneal perfusion chemotherapy with lobaplatin for colorectal cancer. J BUON. 2019;24(2):442-8.

18. Liu Z, Zou Y, Rong Y, et al. Intraoperative chemotherapy with a novel regimen improved the therapeutic outcomes of colorectal cancer. J Cancer. 2019;10(24):5986-91. https://doi.org/10.7150/jca.35450 published Online First: Epub Date.

19. Yılmaz K, Tüfenkçi $P$, Adıgüzel M. The effects of QMix and EndoActivator on postoperative pain in mandibular molars with nonvital pulps: a randomized clinical trial. Clin Oral Investig. 2019;23(11):4173-80. https://doi.org/10.1007/ s00784-019-02856-6 published Online First: Epub Date.

20. Laufenberg-Feldmann R, Kappis B, Mauff S, Schmidtmann I, Ferner M. Prevalence of pain 6 months after surgery: a prospective observational study. BMC Anesthesiol. 2016;16(1):91. https://doi.org/10.1186/s12871-016-0261-7 published Online First: Epub Date.

21. Dindo D, Demartines N, Clavien PA. Classification of surgical complications: a new proposal with evaluation in a cohort of 6336 patients and results of a survey. Ann Surg. 2004;240(2):205-13. https://doi.org/10.1097/01.sla.0000133 083.54934.ae published Online First: Epub Date.

22. Obrand DI, Gordon PH. Incidence and patterns of recurrence following curative resection for colorectal carcinoma. Dis Colon Rectum. 1997; 40(1):15-24. https://doi.org/10.1007/bf02055676 published Online First: Epub Date.

23. Abreu de Carvalho LF, Scuderi V, Maes H, et al. Simultaneous parenchymapreserving liver resection, cytoreductive surgery and intraperitoneal chemotherapy for stage IV colorectal cancer. Acta Chir Belg. 2015;115(4): 261-7. https://doi.org/10.1080/00015458.2015.11681109 published Online First: Epub Date

24. Wang ZJ, Tao JH, Chen JN, et al. Intraoperative intraperitoneal chemotherapy increases the incidence of anastomotic leakage after anterior resection of rectal tumors. World J Gastrointest Oncol. 2019:11(7):538-50. https://doi.org/10.4251/wjgo.v11.i7.538 published Online First: Epub Date.

25. Leung V, Huang N, Liauw W, Morris DL. High risk features of primary colorectal carcinomas which subsequently undergo peritonectomy. Eur J Surg Oncol. 2016:42(6):836-40. https://doi.org/10.1016/j.ejso.2015.08.161 published Online First: Epub Date.

26. Shepherd NA, Baxter KJ, Love SB. The prognostic importance of peritoneal involvement in colonic cancer: a prospective evaluation. Gastroenterology. 1997;112(4):1096-102. https://doi.org/10.1016/s0016-5085(97)70119-7 published Online First: Epub Date.

27. Feng $L, L i u Y, W u X$, Liu Q, Xia D, Xu L. Safety evaluation of intraoperative peritoneal chemotherapy with Lobaplatin for advanced colorectal cancers. Zhonghua Wei Chang Wai Ke Za Zhi. 2015;18(10):1006-10.

\section{Publisher's Note}

Springer Nature remains neutral with regard to jurisdictional claims in published maps and institutional affiliations.

Ready to submit your research? Choose BMC and benefit from:

- fast, convenient online submission

- thorough peer review by experienced researchers in your field

- rapid publication on acceptance

- support for research data, including large and complex data types

- gold Open Access which fosters wider collaboration and increased citations

- maximum visibility for your research: over $100 \mathrm{M}$ website views per year

At $\mathrm{BMC}$, research is always in progress.

Learn more biomedcentral.com/submission 